\title{
Physicists plot mass production of neutrinos
}

David Adam, London

The Large Hadron Collider may be years from operation, and the Next Linear Collider barely off the drawing-board, but ambitious high-energy physicists already have another project in mind.

Dozens of them met in London last week to lay plans for a neutrino factory that, they say, could shed much-needed light on the burgeoning field of neutrino physics.

Recent experiments have shown that neutrinos, which carry no charge, can oscillate between their different subtypes (see Nature 411, 877; 2001), indicating that they have some mass. Such results have important consequences for the standard model, the theory that describes fundamental particles and their interactions, in which neutrinos had been assumed to have zero mass.

Physicists say that a neutrino factory would enable them to study neutrinos and their oscillations in far greater detail. Most observations so far have been of naturally occurring neutrinos striking the Earth from the Sun and from supernovae, and efforts are under way to study neutrinos produced in particle accelerators and nuclear reactors. But the proposed neutrino factory would produce a much more intense beam for researchers.

Funds are scarce, but Ken Long, a highenergy physicist at Imperial College, London, who organized the recent meeting, says that the project is making steady progress. It will take at least another five years to finalize the design, he says, but initial studies indicate that

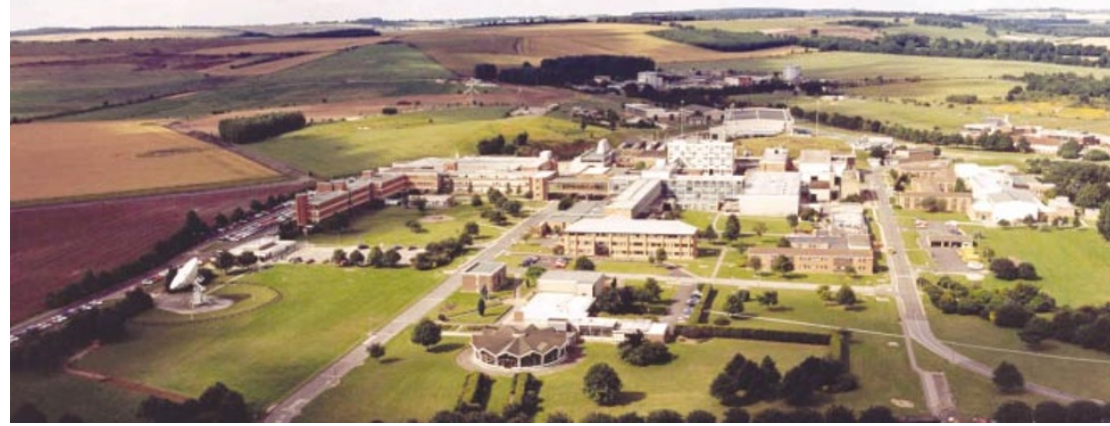

Funds permitting, the Rutherford Appleton Laboratory will test elements needed for a neutrino factory.

the facility could be put into operation by 2015 at a cost of around $£ 2$ billion (US $\$ 3$ billion).

At the heart of any neutrino factory would be a high-power proton beam, which would crash into a solid target to yield an exotic concoction of particles. The factory would purify this mix and use particle accelerators to produce an intense neutrino beam.

To do this, researchers must isolate muons, unstable particles with a mass some 200 times that of an electron, which decay to form neutrinos. "The muons will have a lifespan of only about 2 microseconds," says neutrino researcher Michael Zisman of the Lawrence Berkeley National Laboratory in California. "But that's enough time for us to grab them, shape them, accelerate them and put them into a storage ring — or at least we think it is."

A $£ 20$-million project to test the "muon ionization cooling' concept needed to steer the muons is planned for the Rutherford Appleton Laboratory in Oxfordshire - if funding can be obtained.

Zisman says that a major technical challenge for a neutrino factory is designing a target to withstand the destructive proton beam. One idea is a carbon rod immersed in helium, to slow its physical deterioration. Another would use a jet of liquid mercury.

And some physicists view the neutrino factory as a stepping stone to yet another future project. They think that learning to control and store muons in a neutrino factory would open the way towards building a muon collider (see Nature 394, 611; 1998), which could use the relatively massive particles to yield very high-energy collisions in a machine of a manageable size.

\section{Public body appointed to clean up UK's nuclear legacy}

\section{David Adam, London}

Britain took its first steps towards dealing with its stockpile of nuclear waste last week, when the government announced a new public body to clean up what it terms the country's "nuclear legacy".

The Liabilities Management Authority (LMA) will be responsible for treating and packaging waste from nuclear-fuel reprocessing and contaminated material from nuclear power stations, and for cleaning up their sites and the surrounding land.

But it won't tackle materials from the nuclear-weapons programme or consider the need for long-term waste disposal. Even so, the clean-up is expected to cost some $\mathfrak{E 4 8}$ billion (US\$73 billion) over several decades.

Announcing the plan in a white paper on 4 July, energy minister Brian Wilson pledged that the new authority would implement the clean-up safely, securely and cost-effectively.

The LMA will take over responsibility for the civil nuclear plants operated by the government-owned British Nuclear Fuels Limited (BNFL). But BNFL will continue to operate the sites, including the reprocessing plant at Sellafield in northwest England, under licence. By effectively taking the cost of waste treatment off BNFL's balance sheet, the move opens the door to the partprivatization of the company

Geoffrey Boulton, vice-principal of the University of Edinburgh and chair of a Royal Society working party on the management of radioactive waste, cautiously welcomed the move. "In broad terms it's sensible because something has to be done, but it still needs to be meshed into a more complete solution," Boulton says.

"This is about how to get the waste into the tins, not what to do with the tins," says one official. A separate government consultative process addressing wider issues, including the long-term storage of waste, is expected to report this year.

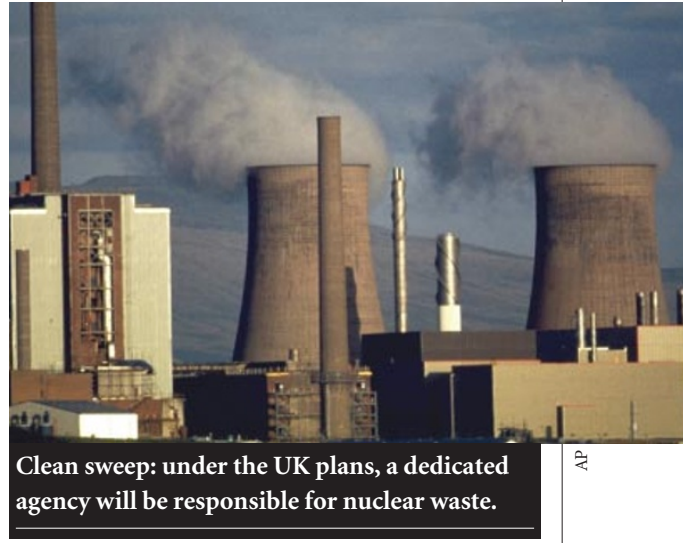

Britain's plans to store nuclear waste permanently were thrown into disarray in 1997, when research into a deep-storage facility at Sellafield collapsed after planning permission for an underground laboratory had been refused (see Nature 386,423 ; 1997). 